\title{
RA?EGA
}

O ESPACYO GEOGRÁFICO EM ANÁLISE

\section{ANTROPOGEOMORFOLOGIA DA BACIA HIDROGRÁFICA DO MURUTUCU: ABASTECIMENTO HÍDRICO, USO E OCUPAÇÃO EM BELÉM-PA ${ }^{1}$}

\section{ANTROPOGEOMORPHOLOGY OF WATERSHED OF MURUTUCU: WATER SUPPLY, USE AND OCCUPACION IN BELÉM, PA}

\author{
Antônio Carlos Ribeiro Araújo Júnior \\ Departamento de Geografia \\ Universidade Federal de Roraima (UFRR) \\ Boa Vista, $R R$ \\ e-mail:aj_geo@hotmail.com
}

Recebido em: 19/08/2014

\section{Resumo}

As Unidades de Proteção Integral estão divididas em Estação Ecológica, Reserva Biológica, Parque Nacional (ou Estadual ou Municipal), Monumento Natural e Refúgio de Vida Silvestre. A Área de Proteção Ambiental de Belém (APA Belém) enquadra-se na categoria Parque Nacional e se deve, sobremaneira, ao fato desta abrigar a fonte de abastecimento de água de toda a Região Metropolitana de Belém (RMB), os lagos Bolonha e Água Preta, além de guardar um ambiente ameno e contemplativo com atrativos turísticos. Apesar de estar inserida na região amazônica, abundante em recursos hídricos, a cidade de Belém e sua região metropolitana, historicamente enfrentam dificuldades de captação, armazenamento e distribuição de água. A antropogeomorfologia considerando as consequências positivas e negativas da ação humana sobre o relevo ajuda a compreender como as formas e processos da Bacia Hidrográfica do Murutucu (BHM) são condicionados para se entender holisticamente quais alterações foram empreendidas nos mananciais do Utinga na BHM tornando mais eficiente o abastecimento hídrico na RMB. As alterações processadas na forma dos lagos mostraram ser necessárias para aumentar seu volume de água e assim atender a demanda crescente da população da RMB denotando que a antropogeomorfologia é um importante instrumento de gestão ambiental.

Palavras-chave: Água, Planejamento, RMB.

\footnotetext{
${ }^{1} \mathrm{O}$ trabalho é fruto do aprofundamento de discussões presentes em "Propostas para subsidiar um plano de ações educativas às comunidades que utilizam diretamente o lago Bolonha, Belém (PA) Revbea, Rio Grande, v. 8, n. 1, p. 50-67, 2013"; e "Indicadores de qualidade ambiental no lago Bolonha, Parque Estadual do Utinga, Belém-Pará - BGG 42 - p. 276-299 - jan. de 2015".
} 


\begin{abstract}
The Integral Protection Units are divided into Ecological Station, Biological Reserve, National Park (or state or municipal), Natural Monument and Wildlife Refuge. The Environmental Protection Area of Belém (Belém APA) fits in category National Park and is due greatly to the fact that this shelter and the source of water supply of all the metropolitan region of Belém (RMB), the Bolonha and Água Preta lakes, and save a mild and contemplative environment with tourist attractions. Despite being inserted in the Amazon region, abundant water resources, the city of Belém and its metropolitan region, historically face funding difficulties, storage and distribution of water. The antropogeomorphology considering the positive and negative consequences of human action on the relief helps to understand how the forms and processes of Watershed Murutucu (BHM) are conditioned to holistically understand what changes were undertaken in Utinga fountains in the BHM to become more efficient the water supply in RMB. Changes processed in the form of lakes shown to be necessary to increase its volume of water and thus meet the growing demand of the RMB population denoting that the antropogeomorphology is an important environmental management instrument.
\end{abstract}

Keywords: Water, Planning, RMB.

\title{
1. INTRODUÇÃO
}

Com a Lei n 9.985/2000, houve a divisão das unidades de conservação em dois grupos, as Unidades de Proteção Integral e as Unidades de Uso Sustentável, cada uma com objetivos específicos legalmente definidos (MAIA NETO, 2009). A Área de Proteção Ambiental (APA) Metropolitana de Belém se enquadra na categoria de Unidade de Proteção Integral, tendo por objetivo, segundo art. $7, \S 1^{\circ}$ "preservar a natureza, sendo admitido apenas o uso indireto dos seus recursos naturais, com exceção dos casos previstos nesta Lei” (BRASIL, 2000).

As Unidades de Proteção Integral estão divididas em Estação Ecológica, Reserva Biológica, Parque Nacional (ou Estadual ou Municipal), Monumento Natural e Refúgio de Vida Silvestre. A APA-Belém enquadra-se na categoria de Parque Nacional, tendo como objetivo básico a preservação, ou seja, para o artigo $2^{\circ}$, capítulo V do SNUC compõe um conjunto de métodos, procedimentos e políticas que visem a proteção, em longo prazo, das espécies, habitats e ecossistemas, além da manutenção dos processos ecológicos prevenindo a simplificação dos sistemas naturais, em certa medida identificando-se com o objetivo da Estação Ecológica (preservação integral da biota). Todavia, acrescentem-se dois novos requisitos, 


\section{ANTROPOGEOMORFOLOGIA DA BACIA HIDROGRÁFICA DO MURUTUCU: ABASTECIMENTO HÍDRICO, USO E OCUPAÇÃO EM BELÉM-PA}

esses ecossistemas devem possuir grande relevância ecológica (requisito intrínseco as demais categorias de unidade) e beleza cênica.

A classificação da APA Metropolitana de Belém se deve ao fato desta abrigar a fonte de abastecimento de água de toda a Região Metropolitana de Belém, os lagos Bolonha e Água Preta, além de guardar um ambiente ameno e contemplativo com atrativos turísticos (caso das ruínas do Murutucu e sua história). Por fim, o SNUC registra que "as unidades dessa categoria, quando criadas pelo Estado ou Município, serão denominadas respectivamente, Parque Estadual e Parque Natural Municipal" (artigo 11, $\S 4^{\circ}$ ). Legalmente o Parque Estadual do Utinga (PEUT) está inserido na APA da RMB, compondo um mosaico de Unidades de Conservação (UCs).

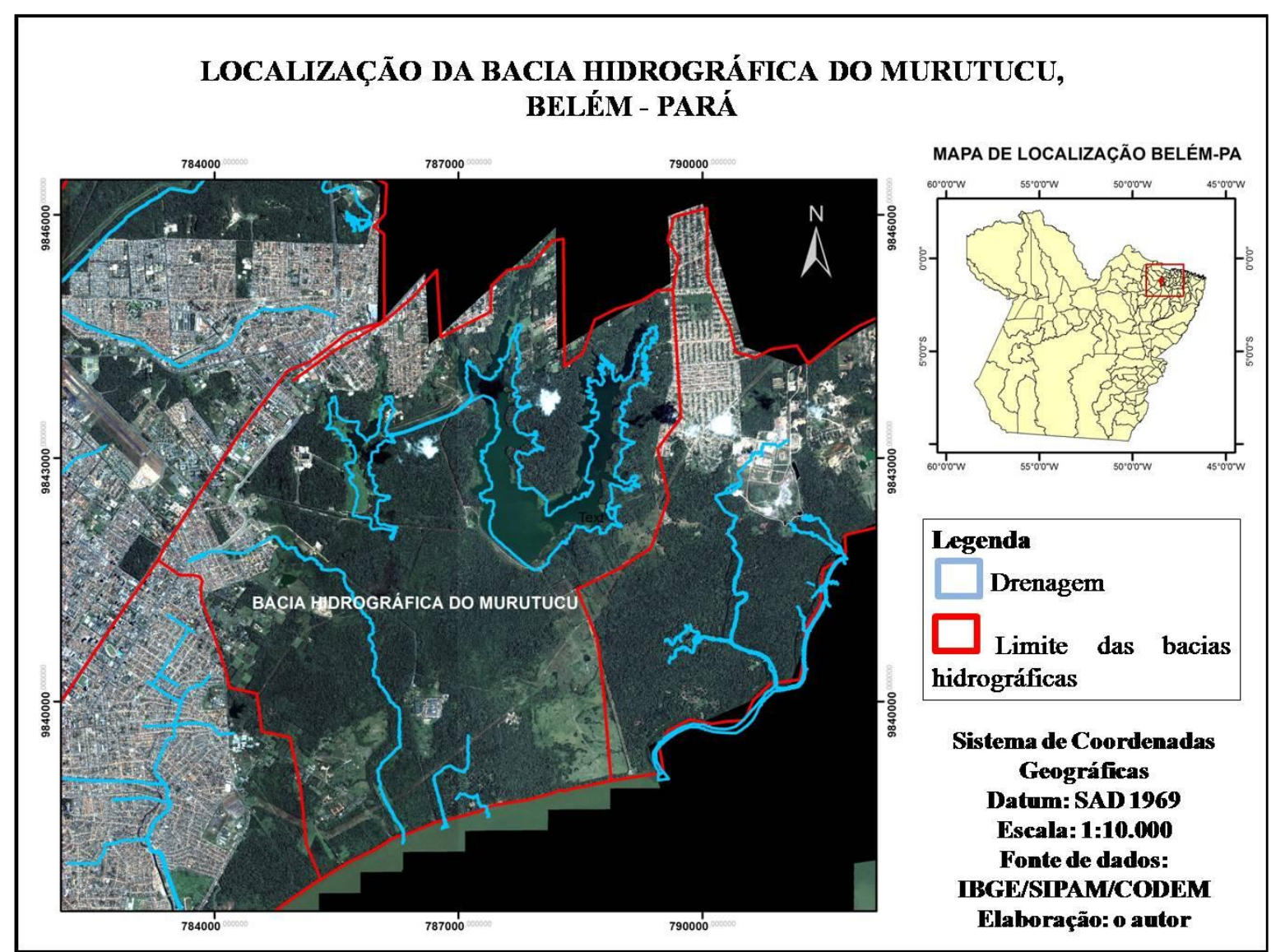

Figura 1: mapa de localização da área de estudo.

Os lagos Bolonha e Água Preta são a principal fonte de abastecimento de água da RMB e são abastecidos pelas águas de microbacias hidrográficas que 
convergem para eles, bem como por um sistema de bombeamento das águas do rio Guamá (adutora) ligado somente ao lago Água Preta, este por sua vez escoa a maior parte dessa água para o lago Bolonha, no qual o processo de limpeza da água para distribuição a RMB é realizado.

O sistema de adutora e o canal artificial que interliga os dois lagos foram implantados pela Companhia de Saneamento do Pará (COSANPA), que tem por objetivo suprir o "déficit" de água destinada ao abastecimento de Belém e municípios vizinhos (MENEZES et al., 2002). Em sua totalidade o conjunto é denominado como Mananciais do Utinga.

Os mananciais de abastecimento de água da RMB (lago Bolonha e lago Água Preta) nos últimos anos vêm sendo "pressionados" pela RMB, por ter que suprir com água potável de boa qualidade uma área de $2.536,888 \mathrm{~km}^{2}$ da qual fazem parte os municípios de Ananindeua, Belém, Benevides, Marituba, Santa Bárbara do Pará e Santa Isabel do Pará somando uma população de 2.581.661 habitantes de acordo com dados do IBGE (2014).

Porém, há de se ressaltar que problemas envolvendo o abastecimento de água no município de Belém e, posteriormente com sua criação, a RMB não são atuais e afligem o poder público, bem como a população do referido município/região desde o período colonial, no qual por apresentar baixa demografia se fazia suficiente o abastecimento oriundo dos poços do Paul d'Água, que se localizavam na hoje conhecida Av. Governador José Malcher esquina com a Travessa da Piedade (FEITOSA, 1994).

Várias foram as alternativas pensadas ao longo do tempo para suprir com água potável a população de Belém e posteriormente de sua RMB, envolvendo processos de drenagem de áreas adjacentes às fontes de abastecimento, por conta de condições naturais insalubres e mesmo o cercamento de determinadas áreas para se evitar o uso e a ocupação, impedindo posterior degradação do meio biofísico.

Neste contexto, objetiva-se entender quais alterações foram empreendidas nos mananciais do Utinga na Bacia Hidrográfica do Murutucu (BHM) para tornar mais eficiente o abastecimento hídrico na RMB. As variáveis uso e ocupação serão analisadas a partir de uma perspectiva holística, por meio do viés sistêmico, 
buscando uma compreensão da realidade integrando o político, o econômico e o ambiental.

\section{MATERIAIS E MÉTODOS}

Para delimitação da Área de Proteção Ambiental (APA) e do Parque Estadual do Utinga (PEUT) foram utilizados os shapes files disponíveis no banco de dados do Instituto de Desenvolvimento Social do Pará (IDESP) e do Instituto Brasileiro de Geografia e Estatística (IBGE), os quais foram processados no software ArcGis 9.3.

Dados do IBGE também foram utilizados para retratar o crescimento da população do município de Belém por meio da elaboração de gráficos e mapas, assim como foram utilizados documentos da Companhia de Saneamento do Estado do Pará (COSANPA) para a construção dos quadros que caracterizam o processo de ampliação dos lagos e, em certa medida, sua desnaturalização, pois há alteração em suas cotas, áreas e volumes.

Os esboços do crescimento populacional são uma adaptação dos disponibilizados pela Prefeitura Municipal de Belém para retratar a expansão do município para oeste, direção a qual estão localizadas as fontes de abastecimento de água, para se analisar possíveis pressões socioambientais sobre os corpos d'água da Bacia Hidrográfica do Murutucu (BHM).

Uma carta-imagem disponível no Google Imagens foi adaptada para caracterizar a pressão exercida pela população da cidade de Belém sobre as fontes de abastecimento de água e para mostrar como a APA funciona como elemento detentor do avanço do uso e ocupação urbana nas porções norte-nordeste e nortenoroeste.

A abordagem sistêmica foi aportada em levantamentos bibliográficos e documentais históricos, os quais contribuem para entender as transformações ocorridas na BHM. O recorte histórico empreendido remete 80 anos, de 1930 a 2010, período em que ocorreram várias ampliações dos lagos Bolonha e Água Preta, bem como a gênese de formas necessárias para plena adaptação espacial às condições adversas de abastecimento de água da RMB. 
A revisão sobre o aporte teórico e conceitual da Geomorfologia Ambiental subsidia o domínio prático-aplicativo da antropogeomorfologia, a qual instrumentaliza fazeres propícios a uma gestão ambientalmente viável e sustentável da água utilizada para abastecimento da RMB.

\section{RESULTADOS E DISCUSSÃO}

O recorte temporal englobou os períodos de 1930 - 1960; 1960 - 1990 e 1990 - 2010, para se dimensionar as alterações que foram empreendidas sobre a fonte de água potável da RMB que é o lago Bolonha situado na Área de Proteção Ambiental de Belém (APA-Belém). Além disso, a análise antropogeomorfológica subsidiou o entendimento das intervenções sociais sobre os lagos e das nuances de sua intervenção.

\subsection{Abastecimento de água potável na RMB pelo lago Bolonha, durante os períodos de 1930 a 1960, 1960 a 1990 e 1990 a 2010}

\section{a) $1930-1960$}

Data de 1907, no Governo do Dr. Augusto Montenegro o início de uma obra pública referente a ampliação no abastecimento de água à população da capital do estado do Pará, constituindo uma de suas primeiras preocupações. Seus objetivos estavam ligados a aumentar a produção/captação de água do Utinga, assim como melhorar a canalização, enterrando a rede de canos que foi encomendada (FEITOSA, 1994, p. 163).

Para alcançar o primeiro objetivo foi determinada a captação de água do Utinga por meio de galerias subterrâneas filtrantes. Para se projetarem esses serviços, foram feitos estudos em toda a bacia do Murutucu, já por meio de alinhamentos, nivelamentos e seções transversais, assim como estudo de toda a zona que influenciava as nascentes.

Faz-se importante mencionar que foi construída uma represa em torno da bacia do Murutucu e de muros ao longo da "vala" que conduz as águas das nascentes com o intuito de protegê-las, a fim de poder bem aproveitá-las, evitando- 
se, para tanto, o contato com as águas de igapó, as quais por apresentarem segundo Moreira (1976) dificuldade de escoamento ou deficiência de drenagem acabam por se tornar impróprias para o consumo.

Em janeiro de 1932 sob as ordens do Major Interventor Magalhães Barata as obras no Utinga prosseguiram, percebendo-se que as condições do abastecimento e distribuição de água à cidade foram melhoradas, não havendo mais deficiência do precioso líquido, embora a rede geral ainda se ressentir de imperfeições devidas ao estado do material antigo que ainda compunha a infraestrutura (FEITOSA, 1994). Houve para isso a construção do canal de Água Preta, denominado na época como Yuna.

Em 1945 na segunda interventoria de Magalhães Barata teve início às obras de completa remodelação dos sistemas de esgoto e abastecimento de água, para tanto em 19 de abril de 1945 foi feito contrato entre o Governo do Estado do Pará e a firma Byington \& CIA, responsável técnica pelo desenvolvimento de tais atividades.

Após minuciosa análise técnica, a firma contratante previu depois do levantamento geral do terreno uma possibilidade de aumentar o volume d'água construindo represas de concreto para maior segurança e mesmo para não haver fuga de água, pois foi verificado que se perdia mais pelos sangradouros do que era enviado para Belém, tudo isso pela falta de segurança do aterro que servia de barragem (FEITOSA, 1994).

Segundo Feitosa (1994) este laudo deu origem a abertura de um novo canal de 1.300 metros de comprimento por 40 de largura e toda a terra deste canal serviu às novas represas do Bolonha e Yuna, que foram construídas pela Companhia contratada.

b) $\mathbf{1 9 6 0 - 1 9 9 0}$

Devido o aumento demográfico da cidade de Belém (gráfico 1), foi instalada uma bomba de recalque para captar água do rio Guamá e completar o abastecimento que o sistema de lagos do Utinga já não atendia na fase de estiagem. Em 1968 procedeu-se à ampliação da capacidade de bombeamento, agregando outro sistema de bombas e aumentando o diâmetro da adutora entre o Guamá e o Utinga (IDESP, 1991). 


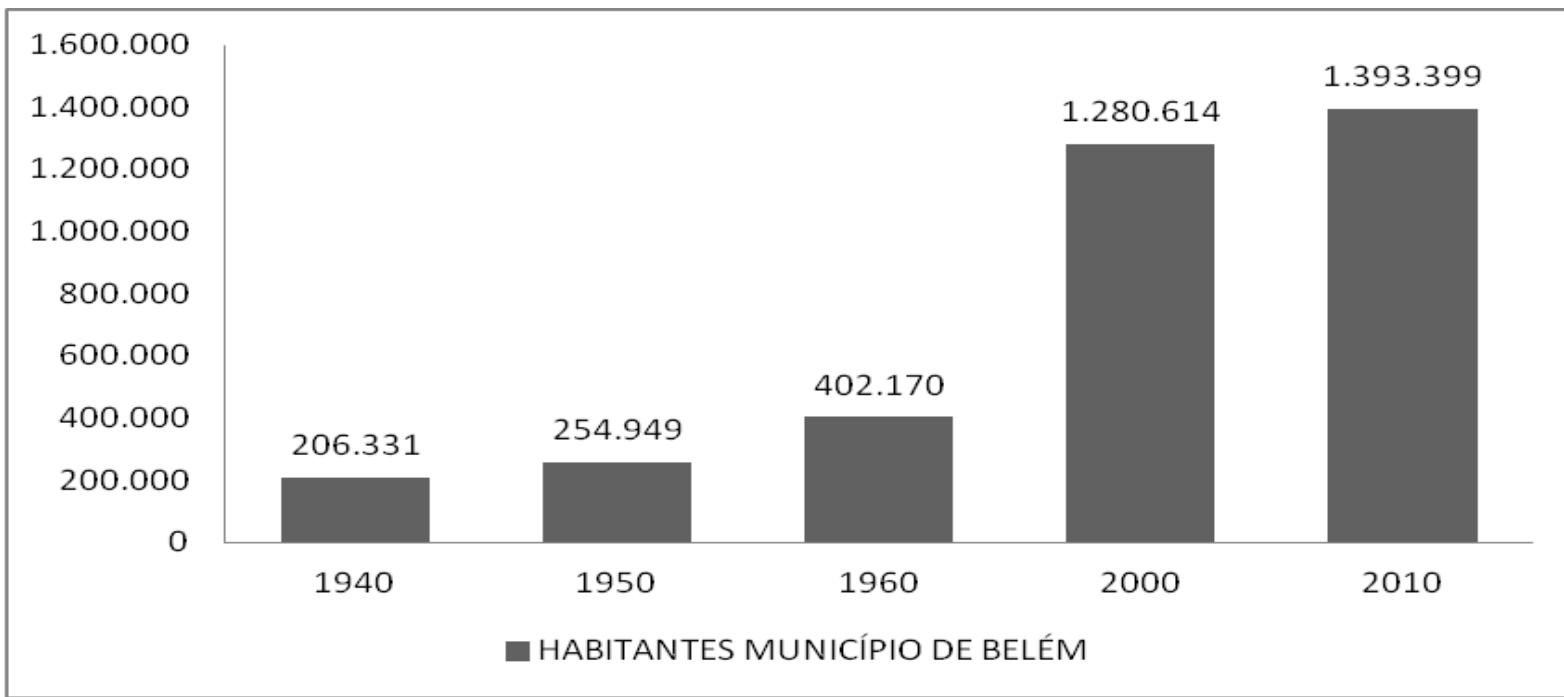

Gráfico 1: Número de habitantes no município de Belém (PA)

Fonte: IBGE

Durante a década de 1970 foram empreendidas análises das alternativas de ampliação do sistema de abastecimento de água da RMB.

Segundo os cálculos da equipe técnica da COSANPA, a Região Metropolitana de Belém já no ano de 1980 teria uma deficiência de água de 1,83 m³/s. Em 1985 este déficit aumentaria para $3,24 \mathrm{~m}^{3} / \mathrm{s}$. Isto já podia ser observado naquele momento, pois já existia falta de água em muitas regiões, fato agravado por estiagens (COIMBRA; SOUZA, 1979).

Deflagrado o problema, metas foram traçadas para que um trabalho de praticamente duplicação da capacidade de abastecimento de água de Belém se iniciasse, delineando alternativas de expansão do sistema com capacidade para atender uma demanda de $6 \mathrm{~m}^{3} / \mathrm{s}$, o que corresponderia a suprir as necessidades da região até por volta de 1986, sendo técnica e economicamente a mais recomendável, bem como considerar a possibilidade de modular o sistema fazendoo ter um alcance maior, além do ano 2000.

Coimbra; Souza (1979) mostraram pelo exame do posicionamento que o rio Guamá reunia o maior potencial para abastecimento de Belém. Contudo, a influência das marés no rio Guamá, implica altos teores de salinidade em certas épocas e em péssimas condições bacteriológicas, levando à cogitação de se utilizar outros mananciais: 1 - Rio Caraparu; 2 - Rio Benfica; 3 - Rio Acará e 4 - Águas Subterrâneas; 
Porém, questões como distâncias, condições fluviométricas de potencial abastecedor, capacidade topográfica da região, longos prazos exigidos para a implantação e falta de dados de pesquisa, constituíram fatores negativos em face da condição de emergência que a RMB enfrentava no concernente ao abastecimento de água.

A opção mais viável apresentada foi a melhoria e expansão do sistema Utinga já existente. Pode-se citar como vantagens de utilização do rio Guamá, acoplado a um sistema de reservação (Água Preta e/ou Bolonha), segundo Coimbra; Souza (op cit.) os seguintes elementos:

- Aproveitamento do sistema existente, que já garantia $3 \mathrm{~m}^{3} / \mathrm{s}$;

- Exige um prazo menor para projeto e execução; e

- O potencial abastecedor do rio Guamá é quase ilimitado, ficando garantidas as demandas futuras e as próximas etapas.

As restrições existentes à utilização do rio Guamá como aparecimento esporádico de altos teores de salinidade e o permanente péssimo estado bacteriológico, são contornáveis.

A portaria no 56/BSB de 14 de março de 1977, do Ministério da Saúde, que tratava do Padrão de Potabilidade válido em todo o território nacional, fixava o Valor Máximo Desejável (VMD) para o teor de cloretos em $200 \mathrm{mg} / \mathrm{l}$, valor acima do qual a água tende a ser menos aceitável pelo consumidor. Como a salinidade é totalmente inócua à saúde, o mesmo Padrão fixa em 600 mg/l o Valor Máximo Permissível (VMP), embora haja locais no mundo onde se consome sem problemas águas com até $2.000 \mathrm{mg} / \mathrm{l}$ de cloretos.

Foi considerado para fins de consumo que de qualquer forma as salinidades maiores que as desejáveis significam a existência de ligeiro sabor salino, o qual pode passar despercebido pela maioria dos usuários. Em termos do Padrão de Potabilidade Coimbra; Souza (1979) falaram da característica sabor e que esta não é limitada numericamente, existindo apenas menção "não objetável", dentro da qual se pode enquadrar perfeitamente a água do rio Guamá.

Quanto ao péssimo estado bacteriológico do rio Guamá, deve-se tecer as seguintes considerações coadunando com Coimbra; Souza (1979):

- Este problema deve ser tratado no Projeto de lançamento dos esgotos de Belém 
e quanto da sua construção deverá, então, ser anulado ou minimizado;

- Trata-se de uma contaminação não-conservativa, facilmente depurável em sistemas naturais como reservatórios;

- É possível lançar mão de tecnologia de desinfecção eficiente para utilização segura da água do rio Guamá; e

- Se os itens anteriores sejam insuficientes, é possível lançar mão do tratamento das águas residuárias que são lançadas no Guamá e na Baía do Guajará, extirpando certamente o problema.

Tendo-se revelado o rio Guamá como escolha acertada, técnica e economicamente, tratou-se de estudar alternativas que aproveitassem, no todo ou em partes, o Sistema Utinga existente. Constituíam-se em opções para ampliação e melhoria do Sistema Utinga as medidas expostas no quadro síntese abaixo (quadro $1)$.

O quadro 1 permite apreender que passando a considerar a captação no rio Guamá e tendo-se revelado como melhor a opção reservação, apresentaram-se para consideração as seguintes alternativas de reservação segundo Coimbra; Souza (1979):

- Utilizar apenas o lago Água Preta, nas condições apresentadas, isto é, com nível máximo de água na cota $8,25 \mathrm{~m}$;

- Utilizar o lago Água Preta na cota 8,25 m e o lago Bolonha na cota 7,50 m, construir um canal de ligação entre os dois lagos e realizar a tomada de água para a Elevatória do Utinga no lago Bolonha;

- Construção de um canal de ligação entre os dois lagos, estes funcionando como vasos comunicantes, elevação da cota do vertedor do Bolonha para 8,25 m, tomada d'água no Bolonha, havendo necessidade de construção de um dique no Bolonha com cerca de 70 metros de comprimento e altura 1,25 metros;

- Utilizar apenas o lago água Preta, elevando o seu vertedor para a cota 9,00 m, havendo necessidade de construção de um dique no Água Preta com cerca de $200 \mathrm{~m}$ de comprimento e altura de 1,75 m;

- Construção do canal de ligação, elevação do vertedor do Água Preta para a cota de 9,00 m, tomada d'água no lago Bolonha, havendo necessidade de um dique no Água Preta com $200 \mathrm{~m}$ de comprimento e altura de 1,75 m. 
- Construção do canal de ligação, elevação dos vertedouros dos lagos Água Preta e Bolonha, havendo necessidade de construção de dois diques, um no Água

Preta com cerca de $200 \mathrm{~m}$ de comprimento e altura de 1,75 m, e outro no Bolonha com 70 metros de comprimento e altura $1,75 \mathrm{~m}$.

\begin{tabular}{|c|c|c|}
\hline ALTERNATIVAS & HIPÓTESE & PERSPECTIVAS \\
\hline $\begin{array}{l}\text { Bombeamento } \\
\text { direto do Guamá }\end{array}$ & $\begin{array}{l}\text { Consistiu em ampliar a captação do rio } \\
\text { Guamá no local atual, e aduzir } \\
\text { diretamente para o Utinga ou outro local; }\end{array}$ & $\begin{array}{l}1 \text { - não se deveria } \\
\text { fundamentalmente abandonar um } \\
\text { sistema existente de reservação } \\
\text { que, embora em pequena } \\
\text { extensão, realiza a diluição da } \\
\text { salinidade; } \\
2 \text { - a economia obtida pela não } \\
\text { utilização de reservatório pode ser } \\
\text { suplantada pelo incremento dos } \\
\text { custos no tratamento de uma água } \\
\text { de pior qualidade; }\end{array}$ \\
\hline $\begin{array}{l}\text { Utilização de } \\
\text { reservatórios }\end{array}$ & $\begin{array}{l}\text { Manutenção da capacidade de } \\
\text { reservação, ou sua expansão, que } \\
\text { poderia ser conseguida por interligação } \\
\text { dos lagos Água Preta e Bolonha, } \\
\text { elevação da cota do nível da água, e até } \\
\text { mesmo por escavação e dragagem; }\end{array}$ & $\begin{array}{l}1 \text { - aproveitar o sistema existente } \\
\text { ao máximo; } \\
2 \text { - embora em pequena escala, } \\
\text { conseguir-se-ia uma diluição de } \\
\text { contaminantes conservativos no } \\
\text { reservatório, inclusive } \\
\text { salinidade; } \\
3 \text { - os pequenos prazos de projeto } \\
\text { e execução exigidos pela situação } \\
\text { de quase emergência, e passíveis } \\
\text { de se obter em algumas das } \\
\text { alternativas de reservação; }\end{array}$ \\
\hline $\begin{array}{l}\text { Captação no } \\
\text { Guamá a } \\
\text { montante }\end{array}$ & $\begin{array}{l}\text { Consiste em construir uma nova } \\
\text { captação no rio Guamá, a montante da } \\
\text { atual, e uma adutora dela ao sistema de } \\
\text { reservação ou diretamente a Elevatória } \\
\text { e/ou Estação de Tratamento do Utinga. } \\
\text { Não se constitui propriamente em uma } \\
\text { opção isolada, pois pode ser } \\
\text { considerada como parte dos casos } \\
\text { anteriores. }\end{array}$ & $\begin{array}{l}\text { 1- apresentava maiores custos; } \\
2 \text { - exigia prazos de projeto e } \\
\text { execução mais longos; } \\
3 \text { - não se podia aproveitar a } \\
\text { captação e adutora existentes } \\
\text { (estas só podem ser desativadas } \\
\text { após o término das novas); } \\
4 \text { - não existiam dados que } \\
\text { comprovassem a sua viabilidade } \\
\text { técnica; }\end{array}$ \\
\hline $\begin{array}{l}\text { Tratamento } \\
\text { especial para } \\
\text { salinidade }\end{array}$ & $\begin{array}{l}\text { Consiste em se realizar a ampliação da } \\
\text { atual captação no Guamá e os } \\
\text { correspondentes aumentos das aduções } \\
\text { até o Utinga, e se construir um sistema } \\
\text { de tratamento de água para remoção de } \\
\text { salinidade logo após o tratamento } \\
\text { convencional existente e/ou a construir. } \\
\text { Tal sistema deveria provavelmente ser } \\
\text { baseado em osmose reversa, } \\
\text { eletrodiálise ou troca iônica. }\end{array}$ & $\begin{array}{l}1 \text { - exigia alto custo de } \\
\text { implantação; } \\
2 \text { - o Brasil não detinha a } \\
\text { tecnologia completa de tratamento } \\
\text { de íons; } \\
3 \text { - todo o equipamento conseguido } \\
\text { com dificuldade e alto custo, só } \\
\text { teria necessidade de ser acionado } \\
\text { em curtos espaços de tempo } \\
\text { (picos de salinidade no Guamá); }\end{array}$ \\
\hline
\end{tabular}

Quadro 1: Alternativas de ampliação do Sistema Utinga

Fonte: adaptado de Coimbra; Souza (1979). 
O recorte temporal foi marcado por uma intensa movimentação no concernente a intervenções que viessem a otimizar o sistema de abastecimento da RMB, no sentido de aumentar a capacidade de distribuição e melhoria qualitativa em seu tratamento.

Há de se destacar também que em fins dos anos 1990 ganhou fôlego uma discussão a cerca de áreas ocupadas próximas aos mananciais, as quais contribuíram direta e decisivamente para um comprometimento do sistema. Tais discussões foram levadas ao governo do estado, o qual a partir daí passou a tomar medidas para sanar problemas envolvendo o uso e a ocupação das áreas dos mananciais do Utinga.

c) $1990-2010$

No sentido de desapropriação da área de proteção sanitária e de preservação dos mananciais novas medidas foram tomadas. Em abril de 1994 quando o Governador Jader Fontenelle Barbalho baixou dois decretos o de no 3.251 que, em seu Art. $1^{\circ}$ declara de utilidade pública para fins de desapropriação, a área de proteção sanitária, lago Bolonha e Água Preta, em Utinga com dimensão de 1.598 ha, alcançando parte dos municípios de Belém e Ananindeua; e o decreto ํo 3.252 que define em seu Art. 1ํㅡㄹ como área de proteção especial para fins de preservação dos mananciais da RMB, os terrenos que integram as Bacias Hidrográficas e a área de proteção sanitária dos lagos em Utinga, com áreas aproximadas de 1.825,20 ha e 1.598,10 ha, respectivamente alcançando também parte dos municípios de Belém e Ananindeua (IDESP, 1991).

Cada vez mais se tornou evidente a ocupação por várias comunidades no entorno dos lagos (figura 2) culminando na criação da APA dos Mananciais de Abastecimento de Água de Belém (APA), o qual foi implantado oficialmente em três de maio de 1993, através do Decreto Estadual ํㅜ 1.551, possuindo uma área de 10.000 hectares. Dentro da APA foi criado o Parque Ambiental de Belém, através do Decreto lei 1.552, também em três de maio de 1993, a área total do Parque Ambiental é de 1.340 hectares (PARÁ, 1993).

O processo de criação da APA gerou desentendimentos entre a população e o governo do estado pela forma como foi conduzida a implantação da mesma, 


\section{ANTROPOGEOMORFOLOGIA DA BACIA HIDROGRÁFICA DO MURUTUCU: ABASTECIMENTO HÍDRICO, USO E OCUPAÇÃO EM BELÉM-PA}

desconsiderando a população ai residente, fazendo com que houvesse a criação de fóruns de entidades para discutir o problema.

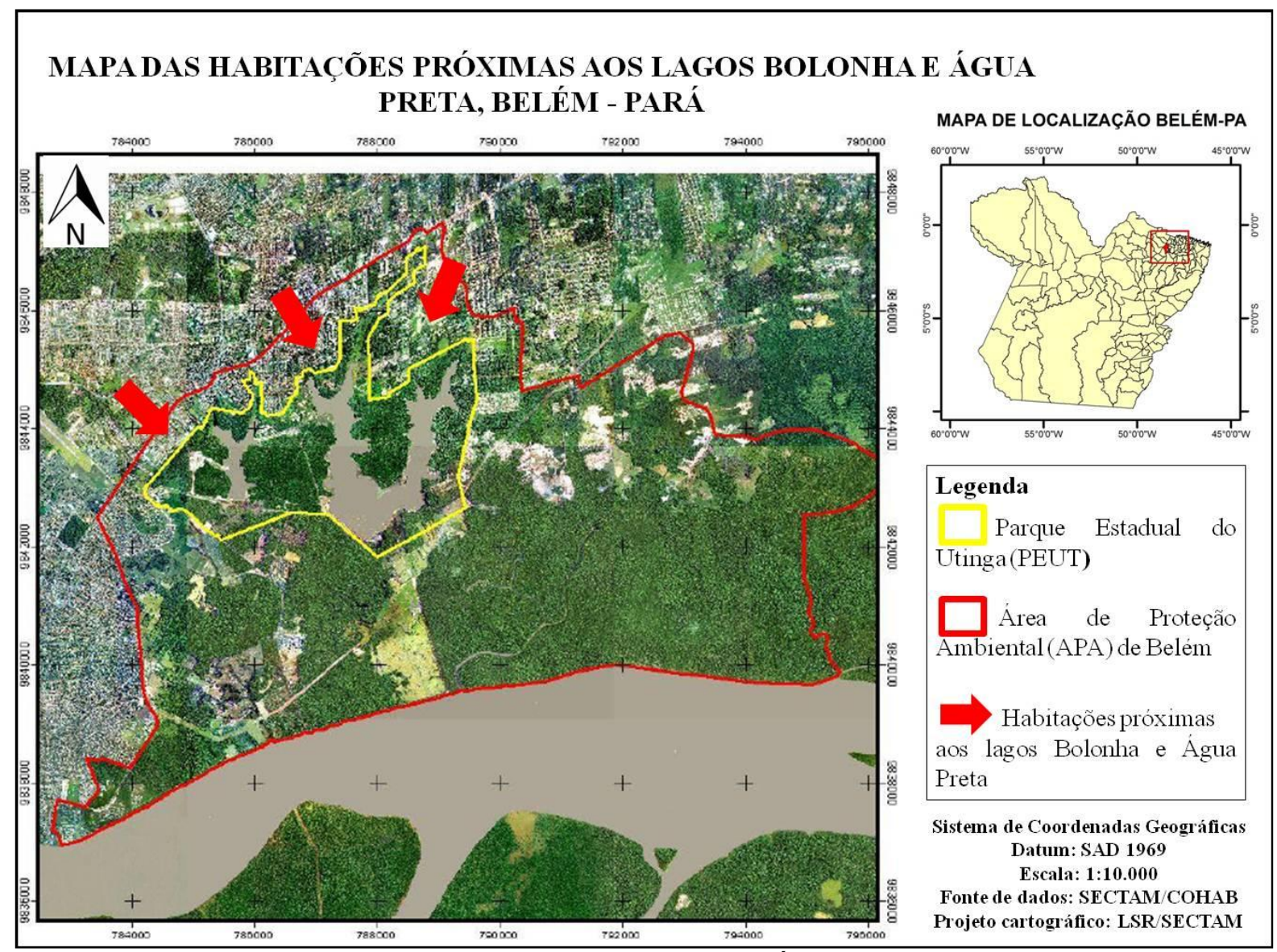

Figura 2: Pressão urbana exercida sobre os lagos Bolonha e Água Preta.

Fonte: Setor de Geoprocessamento da Secretaria Estadual de Meio Ambiente (SEMA), 2010, e Google imagens adaptado pelo autor.

Cabe destacar que no período entre os anos de 1993 e 2003 a APA só existiu no papel, uma vez que durante esses dez anos o processo de implantação aconteceu de forma arbitrária por desconsiderar a presença da população nativa, residentes acerca de 30 ou mais anos no local.

No processo de implantação da APA foram desapropriadas 882 residências e ainda faltariam 311 (IDESP, 1991). Os moradores que continuaram na área não aceitaram a formação de valores de indenização das benfeitorias estabelecidas pela Companhia de Habitação do Pará (Cohab).

No dia 23 de março de 2003 foi realizado um encontro promovido pelo Fórum dos Lagos, que consolidou o movimento e integrou novas entidades de Bairros do entorno. Neste Fórum foi ressaltada a importância da preservação da área e as 
possibilidades de melhor convivência entre famílias e o meio ambiente naquele espaço. Esse encontro foi centrado na importância da maior participação dos moradores da área no processo de implantação da APA - Belém.

Nos últimos 4 (quatro) anos o espelho d'água do lago Bolonha foi sendo tomado por um tipo de vegetação que recebe o nome de macrófita, a espécie encontrada no lago é predominantemente de aguapés (Eichhornia crassipes Solms), e seu surgimento pode estar ligado tanto a própria dinâmica do meio físico, bem como ao aporte de nutrientes em razão da ocupação "desordenada" as margens do lago, ou as duas atuando conjuntamente.

A averiguação do crescimento exponencial desse vegetal no espelho d'água do lago Bolonha será realizada a luz de um viés geográfico, tentando encadear um estudo holístico abarcando a dinâmica do meio bio-físico e do meio antrópico.

\subsection{Antropogeomorfologia do lago Bolonha e sua relação com a expansão urbana da RMB}

Elorza (2007) e Felds (1958) falam que através da história as atividades humanas têm modificado a superfície da Terra, originando novos relevos e destruindo outros e sendo a geomorfologia o estudo das formas do relevo, não deve relegar a atuação da sociedade no processo de gênese morfológica, uma vez que as formas de uso e ocupação da terra denunciam, usualmente, as políticas de organização e apropriação do espaço regional pelos diversos atores sociais, sejam eles os tomadores de decisão política, empresários de diversos setores ou mesmo a comunidade civil (NASCIMENTO; CARVALHO, 2003; FRANÇA; SOUZA, 2013).

Estudos de caráter escalar pontual (até 1:50.000) vêm mostrar uma geomorfologia que considera as transformações empreendidas pela ação humana em uma verdadeira antropomorfogênese de formas na superfície terrestre, deixando vestígios geomorfológicos (FELDS, 1958), criando uma morfologia antropogênica (RODRIGUES, 2005) ou mesmo originando a ocorrência de depósitos tecnogênicos (PELOGGIA, 1997, 2005).

Hooke (2000) diz que o aumento exponencial da população humana e o avanço nas técnicas e tecnologias são fatores que corroboram para uma 
adaptabilidade cada vez maior dos espaços que serão ocupados, alterando sensível ou drasticamente as paisagens, direta ou indiretamente.

Para Moudon (1997) ao se falar sobre a morfologia e como esta vem sendo cada vez mais influenciada pela sociedade, não é mais suficiente entender a construção do espaço e as mudanças na paisagem a partir apenas de seus atributos físicos como na geomorfologia e geologia clássica, mas avançar em estudos interdisciplinares que aliem o físico, o econômico, o político em uma matriz de análise que considere o homem como agente geomorfológico.

Vitte et. al. (2010) e Vitte; Santos (2007) fazem apontamentos sobre o processo de expansão urbana e sua influência sobre as formas e processos do meio físico, gerando, intensificando e transformando o modelado terrestre potencializando o surgir de áreas de risco por tornar as populações, agora residentes em novas áreas, vulneráveis a processos "naturais", bem como por pressionar recursos, neste caso as fontes de abastecimento de água da RMB.

Nascimento (2006) diz que holisticamente infere-se que o ambiente é construído social e historicamente na interação contínua de uma sociedade vivaz e um espaço físico passivo e ativo, concomitantemente. Nesta trajetória são produzidas riquezas a partir da exploração dos recursos naturais, como também impactos socioambientais das mais variadas etiologias e escalas.

Observar o holos é imprescindível, pois o ambiente não representa um fragmento mecânico, mas um grande sistema interconectado em rede e em dinâmica (CAMARGO, 2003). Portanto, como meio global, imbricando três elementos básicos, (i) o entorno natural, (ii) os objetos e artefatos das civilizações humanas, e (iii) o conjunto de todos os fenômenos sociais e culturais que configuram e transformam os indivíduos e os grupos humanos (RODRIGUEZ; SILVA, 2001).

Dimensionar o todo é tarefa salutar e coadunando com Cunha; Guerra (2003) baseados em uma concepção marxista de natureza não dualista, na qual o homem é inserido na história da natureza no Quaternário, a consideração do homem enquanto sociedade - atuando no processo histórico de ocupação e transformação das paisagens dá um caráter dinâmico ao ambiente e nas heranças oriundas das atividades dos grupos sociais, não sendo diferente no espaço belenense. 
Seguindo esta linha, o esforço de Ross (1992) que discutiu a ação humana nas escalas mais locais da taxonomia do relevo, que incide, por exemplo, na dinâmica das vertentes, foi de suma importância para dar corpo à discussão que envolve o homem-sociedade como agente participante no processo dinâmico de modificação das formas componentes no meio natural, nas suas mais variadas dimensões.

Isso leva ao entendimento da Geomorfologia Ambiental, referindo-se à aplicação dos conhecimentos geomorfológicos, ao planejamento e ao manejo ambiental. Também, segundo Guerra; Guerra (2009) inclui o levantamento dos recursos naturais, a análise do terreno, a avaliação das formas de relevo, a determinação das propriedades físicas e químicas dos materiais, o monitoramento dos processos geomorfológicos, as análises de laboratório e a elaboração dos mapas de riscos.

Tais procedimentos têm em consideração as relações socioeconômicas e ambientais como atuantes no tempo e no espaço de forma articulada, considerando natureza e sociedade como responsáveis pela gênese e modificação da paisagem.

Guerra; Guerra (2009), falam ainda que a Geomorfologia Ambiental tem crescido muito nos últimos anos, devido à necessidade de se ocupar novas áreas na superfície terrestre, onde o planejamento ambiental torna-se indispensável para que sejam evitadas catástrofes.

Neste aspecto a Geomorfologia Ambiental interfere no campo das construções civis, do planejamento dos usos da água, das mudanças de regimes pluviométricos, das modificações gerais da paisagem. O objetivo da Geomorfologia Ambiental é minimizar as distorções topográficas, entender e atuar nos processos inter-relacionados para a restauração ou manutenção do balanço natural (PENTEADO, 1980).

Para tanto, Ross (1994) fala que, mais do que atuar de forma corretiva, prevenir torna-se uma alternativa viável por ser economicamente menos custoso prevenir, por exemplo, um acidente ecológico ou degradação generalizada do ambiente, do que corrigir um quadro ambiental degradado.

O viés teórico-conceitual da Geomorfologia Ambiental vai subsidiar estudos antropogeomorfológicos no domínio de sua aplicação. A reflexão 
antropogeomorfológica aproxima o fenômeno de construção do espaço urbano aos estudos da geomorfologia clássica e inaugura um campo de investigação sobre a interface entre o ambiente construído e o natural, em uma antropogeomorfologia urbana (SANTOS FILHO, 2011).

A antropogeomorfologia é aplicada no âmbito do planejamento ambiental no espaço urbano, uma vez que a alteração de espaços para adaptação da sociedade se faz imprescindível para que se processe em termos menos agressivos, com a criação e transformação do relevo, sendo necessário conhecer quais seus agentes e as consequências de suas ações sobre o espaço antropicamente produzido.

À gênese de formas por parte da ação da sociedade chama-se antropogeomorfologia, a qual Rodrigues (2005) define como sendo o estudo do ambiente que resulta da presença e da intervenção antrópica no ambiente, é a relação no tempo e no espaço (NIR, 1983; GOUDIE, 1994), das mudanças no ambiente físico provocadas por ações antrópicas, considerando em sua análise três elementos morfológicos básicos: formas, materiais e processos da superfície terrestre (HART, 1986, apud, SANTOS FILHO, 2011).

Os estudos em antropogeomorfologia se desenvolvem a partir da emergência de pensar o espaço, em especial o espaço urbano, concebendo-o como síntese máxima das alterações no meio físico para adaptabilidade e acomodação no intuito de atender as necessidades básicas do individuo que vive em sociedade (moradia, saneamento básico, locomoção etc.).

A reflexão antropogeomorfológica aproxima o fenômeno de construção do espaço urbano aos estudos da geomorfologia clássica e inaugura um campo de investigação sobre a interface entre o ambiente construído e o natural, em uma antropogeomorfologia urbana (SANTOS FILHO, 2011).

Aplica-se a antropogeomorfologia no âmbito do planejamento ambiental no espaço urbano, uma vez que a alteração de espaços para adaptação da sociedade se faz imprescindível para que se processe em termos menos agressivos, com a criação e transformação do relevo, sendo necessário conhecer quais seus agentes e as consequências de suas ações sobre o espaço antropicamente produzido.

Abastecer a cidade de Belém com o recurso mais imprescindível a vida, a água, fez com que o poder público (municipal e estadual) intervisse no espaço físico 
da bacia hidrográfica do Murutucu (BHM) com o intuito de ampliar o sistema de abastecimento, visando sanar problemas de captação, armazenamento e distribuição do espaço.

O breve resgate empreendido sobre a situação do abastecimento de água na RMB aponta para o que historicamente se constitui em um dos seus grandes problemas, o qual se intensificou a partir das sucessivas ondas de crescimento populacional vivenciadas pela região em questão.

Destaca-se também o fato de que no contexto urbano, a escassez da água é, gerada socialmente por dois motivos: (i) o incremento do consumo habitacional e industrial e (ii) a ampliação da área urbanizada (ver figura 2) com a consequente impermeabilização da superfície, assim como a pressão sobre os mananciais pela diversificação de usos (ROCHA; PEREIRA, 2010).

No período 1960-1990 verificou-se na cidade de Belém e em sua região metropolitana um "progresso" em ritmo acelerado, provocando distorções na ocupação da terra (figura 3), no planejamento e, mormente, nos sistemas de saneamento básico, os quais não conseguiam acompanhar este ritmo. Assim, modificações e alternativas foram pensadas para solucionar um problema secular da cidade e que agora abrange a RMB.

Dentre as diversas hipóteses levantadas e já expostas no subcapítulo anterior o aumento da área, do volume e, por conseguinte das cotas dos lagos Bolonha e Água Preta se mostraram como viáveis do ponto de vista dos custos e tempo de implantação, posto a necessidade imediata deste recurso imprescindível à vida.

Os dados a seguir nos quadros 02 e 03 apresentados por Coimbra; Souza (1979) mostram a relação cota-área-volume para os lagos Bolonha e Água Preta, respectivamente. 


\section{ANTROPOGEOMORFOLOGIA DA BACIA HIDROGRÁFICA DO MURUTUCU: ABASTECIMENTO HÍDRICO, USO E OCUPAÇÃO EM BELÉM-PA}

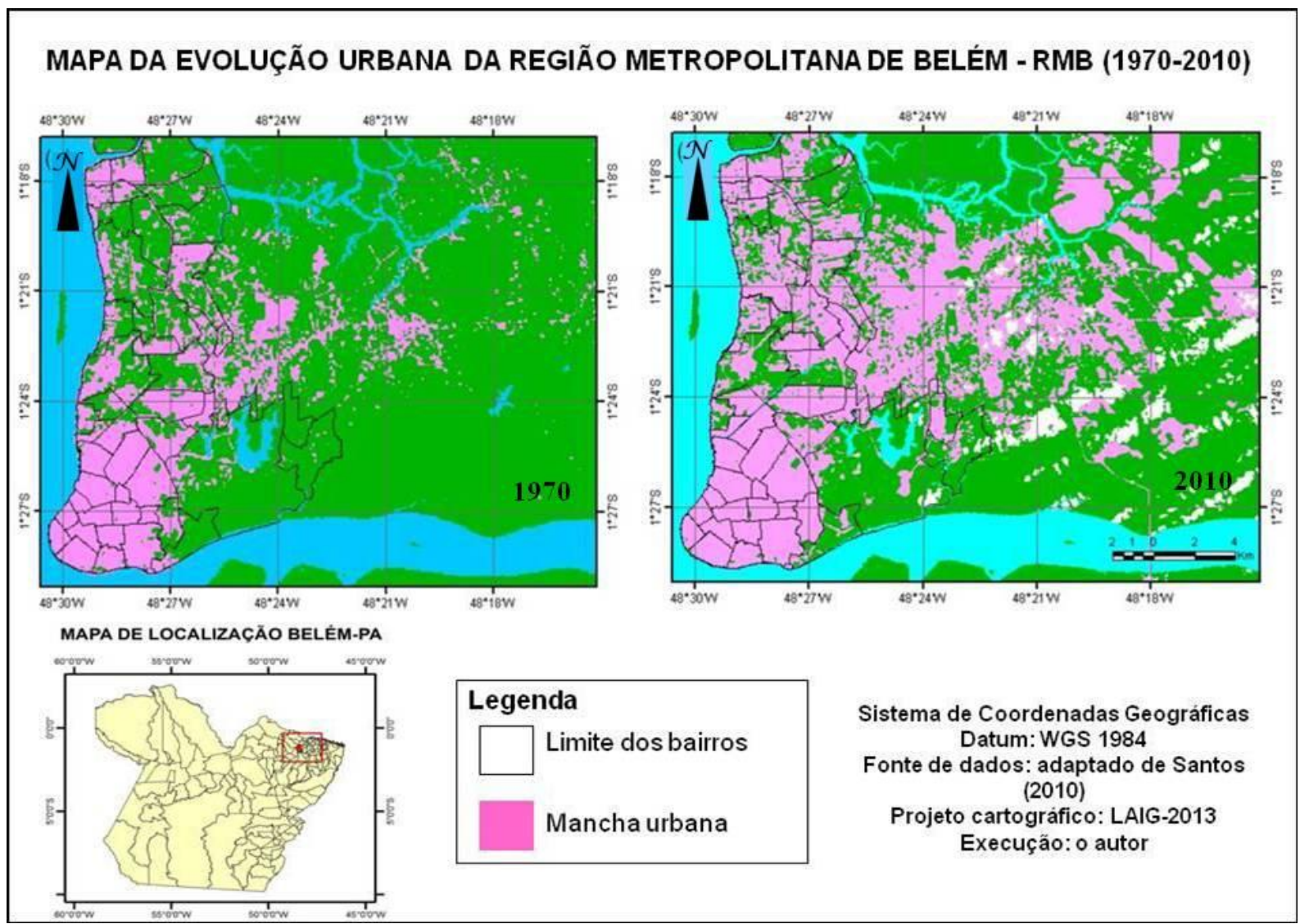

Figura 3: Evolução urbana da RMB.

Fonte: adaptado de Santos (2010) pelo autor.

\begin{tabular}{|c|c|c|c|c|}
\hline COTAS $(\mathrm{m})$ & Área $\left(\mathrm{m}^{2}\right)$ & $\begin{array}{c}\text { Área Acumulada } \\
\left(\mathrm{m}^{2}\right)\end{array}$ & Volume $\left(\mathrm{m}^{3}\right)$ & Volume acumulado $\left(\mathrm{m}^{3}\right)$ \\
\hline 3 & $33.051,38$ & $33.051,58$ & $6.610,28$ & $6.610,28$ \\
\hline 4 & $244.071,72$ & $277.123,10$ & $155.087,24$ & $161.697,52$ \\
\hline 5 & $101.696,55$ & $378.819,66$ & $327.971,38$ & $489.668,90$ \\
\hline 6 & $88.984,48$ & $467.804,14$ & $423.311,90$ & $912.980,79$ \\
\hline 7 & $50.848,28$ & $518.652,41$ & $493.228,28$ & $1.406 .209,07$ \\
\hline 8 & $58.475,52$ & $557.127,93$ & $547.890,17$ & $1.954 .099,24$ \\
\hline 9 & $88.984,48$ & $666.112,41$ & $621.620,17$ & $2.575 .719,42$ \\
\hline 10 & $71.187,59$ & $737.300,00$ & $701.706,21$ & $3.277 .425,62$ \\
\hline
\end{tabular}

Quadro 2: Cotas, Áreas e Volumes do reservatório Bolonha

Fonte: Coimbra; Souza (1979).

\begin{tabular}{|c|c|c|}
\hline COTA $(\mathrm{m})$ & Área $\left(\mathrm{m}^{2}\right)$ Acumulada & Volume $\left(\mathrm{m}^{3}\right)$ Acumulado \\
\hline 3,5 & 396.380 & 46.969 \\
\hline 4,0 & 854.250 & 359.626 \\
\hline 4,5 & 1.523 .770 & 954.131 \\
\hline 5,0 & 2.151 .900 & 1.873 .048 \\
\hline 5,5 & 2.394 .950 & 3.009 .760 \\
\hline 6,0 & 2.558 .914 & 4.248 .226 \\
\hline 6,5 & 2.684 .373 & 5.559 .48 \\
\hline 7,0 & 2.822 .602 & 6.935 .792 \\
\hline 7,5 & 2.969 .060 & 8.383 .707 \\
\hline 8,0 & 3.116 .860 & 9.905 .189 \\
\hline
\end{tabular}

Quadro 3: Cotas, Áreas e volumes do reservatório Água Preta

Fonte: Coimbra; Souza (1979). 


\section{ANTROPOGEOMORFOLOGIA DA BACIA HIDROGRÁFICA DO MURUTUCU: ABASTECIMENTO \\ HÍDRICO, USO E OCUPAÇÃO EM BELÉM-PA}

Os quadros acima mostram algumas das intervenções nos lagos Bolonha e Água Preta para aumentar suas capacidades de vazão e então suprir a RMB, destacando que as linhas marcadas correspondem às cotas, áreas e volumes atuais sendo responsáveis por abastecer a RMB com cerca de $20 \mathrm{~m}^{3} / \mathrm{s}$ de água própria para o consumo.

Os cálculos realizados por Coimbra; Souza (1979) conferem com os dados mais recentes obtidos na Companhia de Saneamento do Pará (COSANPA) no concernente a vazão em m³/s para atender a demanda da RMB, podendo ser melhor visualizados no gráfico 2 a seguir.

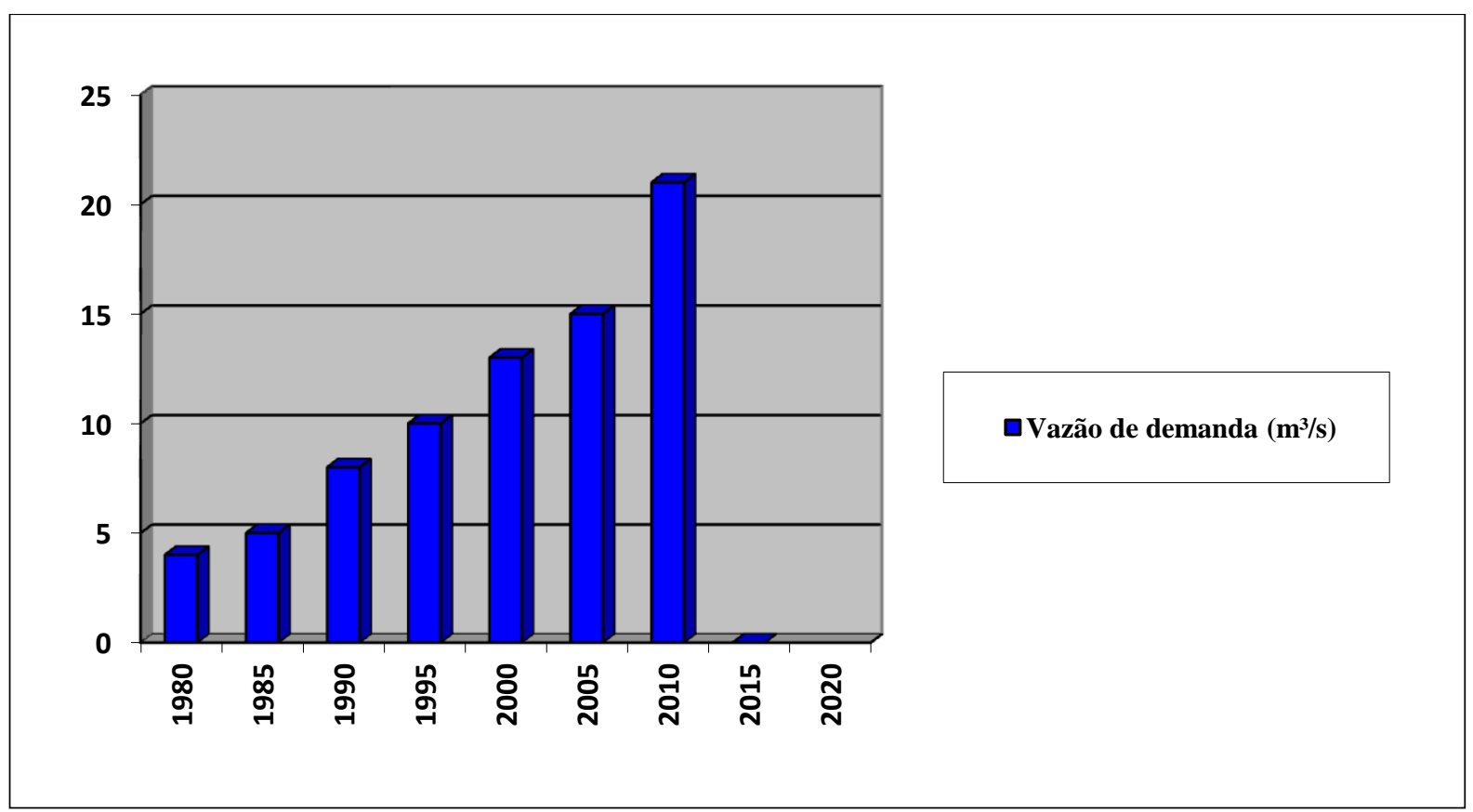

Gráfico 2: Retrospecto e prospectos da Relação vazão/demanda entre os anos de 1980 a 2010 Fonte: Adaptado de COSANPA (2000).

Pode-se depreender então que a ampliação dos sistemas de captação e armazenamento de água da RMB, bem como a construção e ampliação dos lagos Bolonha e Água Preta e institucionalização das áreas onde os mananciais se localizam foram e são processados em razão do aumento populacional e da ocupação de áreas próximas aos mananciais, sendo o espaço testemunho das intervenções técnicas, as quais proporcionaram e proporcionam a melhoria desse sistema de abastecimento. 
A ampliação do sistema de abastecimento de água à RMB se fez/faz importante em função de seu crescimento populacional, no entanto, também existe a necessidade de políticas públicas no sentido de conter o avanço das pressões antrópicas sobre a área dos lagos, impedindo a degradação ambiental a que estão expostos, evitando, como coloca Sodré (2007), que os lagos sejam usados como receptores finais de esgotos domésticos, industriais e águas pluviais lançadas na bacia.

\section{CONSIDERAÇÕES FINAIS}

Entender as alterações processadas na bacia hidrográfica do Murutucu (BHM) a partir da antropogeomorfologia é ratificar que a sociedade tem influência na gênese de formas no espaço, com destaque para as intervenções processadas em microescala, as quais sofrem diariamente adaptações para dar melhores condições de permanência à população.

Considerar a sociedade como agente geomorfológico é reconhecer seu poder de decisão e transformação. No entanto, faz-se importante destacar que estas transformações não se referem às morfoestruturas e morfoesculturas, ou seja, as macroformas do relevo, mas as alterações e gêneses em escala local e possivelmente em escala regional.

Em Belém, a escala local analisada é a BHM, na qual foi possível verificar formas e processos criados, bem como formas e processos induzidos. Como formas criadas e induzidas têm-se os lagos Bolonha e Água Preta, os quais são na realidade açudes (por serem construídos), uma vez que suas Cotas, Áreas e Volumes foram alteradas para acomodação de um quantitativo maior de água, visando o fornecimento presente e futuro, para tanto houve a intensificação do processo de captação da água, o qual tornou-se insuficiente somente pela drenagem da BHM ou da precipitação.

Uma análise primária permite concluir que as intervenções foram executadas de maneira a suprir o sistema de abastecimento de água da RMB, apresentando impacto positivo sobre a população, uma vez que assegura o acesso ao recurso, no entanto, novas medidas precisam ser pensadas para ampliar o sistema de 
abastecimento, visto que mais 5 (cinco) municípios além de Belém fazem uso destas fontes.

Há de se pensar formas alternativas de abastecimento hídrico (outras formas e fontes de captação), as quais acompanhem equitativamente o uso e a ocupação crescente nos centros urbanos como Belém e suas áreas de expansão, uma vez que não somente residências utilizam água, estando ainda empresas e indústrias inseridas neste mercado consumidor.

Conclui-se também que a criação da Área de Proteção Ambiental (APA) de Belém foi fator benéfico e primordial para preservação das fontes de água, mas não foi suficiente, devido os lagos estarem vulneráveis a descarga de esgotos sanitários de comunidades situadas as suas proximidades, havendo necessidade de atuação mais efetiva do poder público estadual responsável pela manutenção do sistema de abastecimento, o qual deve ter a sociedade como agente ativo no processo de utilização e transformação das fontes d'água.

\section{REFERÊNCIAS}

BRASIL. Lei no 9.985, de 18 de julho de 2000. Regulamenta o art. 225, § 1丷, incisos I, II, III e VII da Constituição Federal, institui o Sistema Nacional de Unidades de Conservação da Natureza e dá outras providências. Diário Oficial da República Federativa do Brasil, Brasília, DF, 19 jul. 2000.

CAMARGO, L. H. R. Geografia, Epistemologia e Método da Complexidade. Revista Sociedade e Natureza. 14 e 15 (26 a 29): 133-150. Uberlândia: Edufu, 2003.

COIMBRA, A. R. S. R.; SOUZA, M. A. A. Análise básica das alternativas de ampliação do sistema de abastecimento de água da cidade de Belém-Pará. Brasília-DF. 1979.

COSANPA, Urbanização e medidas de proteção sanitária da região dos lagos Utinga. Relatório técnico 023, 2000.

CUNHA, S. B.; GUERRA, A. J. T. Degradação Ambiental. In: Guerra, A. J. T. e Cunha, S. B. (orgs.). Geomorfologia e Meio Ambiente. $4^{a}$ ed. Rio de Janeiro, 2003. p. 337-380. 
ELORZA, M. G. El papel del hombre em la creación y destrucción del relieve. Revista R. Acad. Cienc. Exac. Fís. Nat. (Esp.), vol. 101, №․ 1, p. 211-216, 2007.

FEITOSA, D. Macrodrenagem e Água Potável em Belém do Pará. Documentário Histórico - Cosanpa. Belém, Multsoft, 1994.

FELDS, E. Geomorfologia Antropogenética. Boletim Geográfico, Rio de Janeiro, v. 16, no. 144, p. 352-357, 1958.

FRANÇA, L. G.; SOUZA, C. J. O. O conhecimento geomorfológico para o Planejamento Municipal: estudo de caso do Município de Juatuba-MG. Caderno de Geografia, v.23, n.40, 2013.

GOUDIE, A. S. The Human Impact in the Natural Environment. 4aㅡ ed. Cambridge (Massachusetts). The MIT Press, 1994.

GUERRA. A. T.; GUERRA. A. J. T. Novo dicionário geológico-geomorfológico. Editora: Bertrand Brasil, 2009.

HOOKE, R. LEB. On the history of humans as geomorphic agents. Geology, v. 28; no. 9; p. 843-846, September 2000.

Instituto Brasileiro de Geografia e Estatística - IBGE, Diretoria de Pesquisas - DPE - Coordenação de População e Indicadores Socias - COPIS, 2014.

Instituto de Desenvolvimento Econômico e Social do Pará - IDESP, Estudo ambiental no Utinga: vida útil do sistema de abastecimento d'água de Belém. Sérgio da Fonseca Dias (coord.). Belém: IDESP, Relatórios de Pesquisa ํㅜ 19, 1991.

MAIA NETO, G. A. Unidades de Conservação de Proteção Integral. Jus Navigandi, Teresina, ano 14, no 2342, 29 nov, 2009.

MENEZES, L. B. C.; BRAZ, V. N.; QUEIROZ, S. A. R.; CUNHA, E. C. S. Perfis de oxigênio dissolvido nos lagos Bolonha e Água Preta, Utinga, Belém-Pa. In: SIMPÓSIO ÍTALO BRASILEIRO DE ENGENHARIA SANITÁRIA E AMBIENTAL, VI, 2002. Espírito Santo, Vitória. Anais... Espírito Santo UFES, 2002.

MOREIRA, E. Os igapós e seu aproveitamento. Cadernos do NAEA, Belém: UFPA, n. 2, 1976. 
MOUDON, A. V. Urban morphology as an emerging interdisciplinary field. Urban Morphology, v. 1, p. 3-10, 1997.

NASCIMENTO, F. R. Degradação ambiental e desertificação no Nordeste brasileiro: o contexto da bacia hidrográfica do rio Acaraú - Ceará. Tese (Doutorado). Programa de Pós-Graduação em Geografia da Universidade Federal Fluminense, uff/Rio de Janeiro, 2006.

NASCIMENTO, F. R do; CARVALHO, O. Bacias hidrográficas como unidade de planejamento e gestão geoambiental: uma proposta metodológica. Revista Fluminense de Geografia. Niterói. № 2, p. 61-82, 2003.

NIR, D. Man, a geomorphological agent: an introduction to anthropic geomorphology. Jerusalém, Ketem Pub. House, 1983.

PARÁ. DECRETO no 1.551 e o 1.552 , de 03 de maio de 1993. Dispõe sobre a Implantação da Área de Proteção Ambiental dos Mananciais de Abastecimento de Água de Belém - APA Belém. Diário Oficial do Estado do Pará, Pará, 03 maio de 1993.

PENTEADO, M. M. Fundamentos de Geomorfologia. $3^{\underline{a}}$ ed. Rio de Janeiro: IBGE, 1980.

PELOGGIA, A. U. G. A cidade, as vertentes e as várzeas: a transformação do relevo pela ação do homem no município de São Paulo. Revista do Departamento de Geografia. São Paulo, n.ำ 16, p. 24-31, 2005.

. A ação do homem enquanto ponto fundamental da geologia do tecnógeno: proposição teórica básica e discussão acerca do caso do município de São Paulo. Revista Brasileira de Geociências.Volume 27, p. 257-268, 1997.

PMB - PREFEITURA MUNICPAL DE BELÉM. Portal da Amazônia: Urbanização da bacia da Estrada Nova e Orla do rio Guamá. Audiência UFPA. PMB/SEURB, 2006.

ROCHA, G. M.; PEREIRA, I. C. N. População e recursos: crescimento populacional e o uso dos recursos hídricos na cidade de Tucuruí/Pa. Disponível em: http://www.abep.nepo.unicamp.br/docs/eventos/transdisciplinar/amb_rocha.pdf.

Acesso em: 03 de outubro de 2010.

RODRIGUES, C. Morfologia original e morfologia antropogênica na definição de unidades espaciais de planejamento urbano: exemplo na metrópole paulista. Revista do Departamento de Geografia, no 17, p. 101-111, 2005. 
RODRIGUEZ, J. M. M; SILVA, E. V. Desenvolvimento local sustentável: Projeto de Educação Ambiental integrado em uma Favela. Primeiro Prêmio Petrobrás. Universidade Solidária: Fortaleza - CE, 2001.

ROSS, J. L. S. Análise empírica da fragilidade dos ambientes naturais antropizados. Revista do Departamento de Geografia. São Paulo, FFLCH-USP, n.ำ 8, p. 63-74, 1994.

O registro cartográfico dos fatos geomórficos e a questão da taxonomia do relevo. Revista do Departamento de Geografia. São Paulo, FFLCH-USP, n.ำ 6 , p.17-29, 1992.

SANTOS, F. A. Alagamento e inundação urbana: modelo experimental de avaliação de risco. Dissertação (Mestrado em Ciências Ambientais) - Programa de Pós-Graduação em Ciências Ambientais, Instituto de Geociências, Universidade Federal do Pará, Museu Paraense Emilio Goeldi e EMBRAPA, Belém, 2010.

SANTOS FILHO, R. D. Antropogeomorfologia Urbana. In: GUERRA, A. J. T (org). Geomorfologia Urbana. Rio de Janeiro: Bertrand Brasil, 2011, p. 227-246.

SODRÉ, S. S. V. Hidroquímica dos lagos Bolonha e Água Preta mananciais de Belém-Pará. Dissertação (Mestrado em Ciências Ambientais) - Programa de PósGraduação em Ciências Ambientais, Instituto de Geociências, Universidade Federal do Pará, Museu Paraense Emílio Goeldi e EMBRAPA, Belém, 2007.

VITTE, A. C.; CISOTTO, M. F.; VILELA FILHO, L. R. A urbanização e a incorporação das várzeas ao espaço urbano de Campinas (SP), Brasil. Revista Geografar. Curitiba, v.5, n.1, p.105-132, jan./jun. 2010.

VITTE, A. C.; SANTOS, J. A. dos. A urbanização e as implicações socioambientais dos conjuntos habitacionais: o caso da cidade de Adamantina (SP). OLAM Ciência \& Tecnologia. Rio Claro/SP, Brasil Ano VII vol. 7, oㅡ 2, p. 87-105, dezembro/2007. 